Article

\title{
Increased Visceral Adipose Tissue and Hyperinsulinemia Raise the Risk for Recurrence of Non-B Non-C Hepatocellular Carcinoma after Curative Treatment
}

\author{
Kenji Imai *, Koji Takai, Takao Miwa, Toshihide Maeda, Tatsunori Hanai $\mathbb{D}^{\text {, }}$, Makoto Shiraki, Atsushi Suetsugu \\ and Masahito Shimizu (1)
}

Citation: Imai, K.; Takai, K.; Miwa T.; Maeda, T.; Hanai, T.; Shiraki, M.; Suetsugu, A.; Shimizu, M. Increased Visceral Adipose Tissue and Hyperinsulinemia Raise the Risk for Recurrence of Non-B Non-C Hepatocellular Carcinoma after Curative Treatment. Cancers 2021, 13, 1542. https://doi.org/10.3390/ cancers13071542

Academic Editors: Nathan A. Berger and J. Mark Brown

Received: 18 February 2021

Accepted: 24 March 2021

Published: 26 March 2021

Publisher's Note: MDPI stays neutral with regard to jurisdictional claims in published maps and institutional affiliations.

Copyright: (c) 2021 by the authors. Licensee MDPI, Basel, Switzerland. This article is an open access article distributed under the terms and conditions of the Creative Commons Attribution (CC BY) license (https:/ / creativecommons.org/licenses/by/ $4.0 /)$.
Department of Gastroenterology/Internal Medicine, Gifu University Graduate School of Medicine, 1-1 Yanagido, Gifu 501-1194, Japan; koz@gifu-u.ac.jp (K.T.); takao.miwa0505@gmail.com (T.M.); toshi_z218@yahoo.co.jp (T.M.); hanai0606@yahoo.co.jp (T.H.); mshiraki-gif@umin.ac.jp (M.S.); asue@gifu-u.ac.jp (A.S.); shimim@gifu-u.ac.jp (M.S.)

* Correspondence: ikenji@gifu-u.ac.jp; Tel.: +81-(58)-230-6308; Fax: +81-(58)-230-6310

Simple Summary: With the increasing prevalence of obesity and diabetes in most countries, the increase in hepatocellular carcinoma (HCC) associated with these factors has recently become a serious healthcare problem. HCC can often emerge in the non-cirrhotic liver among obese patients, and it might suggest that the conventional surveillance strategies for HCC, which is mainly targeted at cirrhotic patients with hepatitis $B$ or $C$ virus, might be insufficient in the overnutrition era. We tried to extract factors that affect recurrence-free survival in patients with non-viral HCC, among obesity and diabetes factors, together with the established recurrence risk factors, using a decision-tree analysis.

Abstract: We investigated the factors affecting recurrence-free survival in patients with non-B non$\mathrm{C}$ hepatocellular carcinoma (HCC) who received curative treatment. Decision-tree analysis was performed in 72 curative cases of non-B non-C HCC to extract the risk factors for recurrence. The reliability of the extracted risk factors was evaluated using the Kaplan-Meier method and the Cox proportional hazards model. The decision-tree analysis extracted three factors-visceral adipose tissue (VAT) index (VATI; $<71$ and $\geq 71 \mathrm{~cm}^{2} / \mathrm{m}^{2}$ ), which was the cross-sectional areas of VAT on the computed tomographic image at the umbilical level, normalized by the square of the height, fasting immunoreactive insulin (FIRI; $<5.5$ and $\geq 5.5 \mu \mathrm{U} / \mathrm{mL}$ ), and alpha-fetoprotein (AFP; $<11$ and $\geq 11 \mathrm{ng} / \mathrm{mL}$ ). The Cox proportional hazards model showed that VATI (hazard ratio (HR): $2.556,95 \%$ confidence interval (CI): 1.191-5.486, $p=0.016$ ), FIRI (HR: 3.149, 95\% CI: 1.156-8.575, $p=0.025$ ), and AFP (HR: 3.362, 95\% CI: 1.550-7.288, $p=0.002$ ) were all independent risk factors for HCC recurrence. Non-B non-C HCC patients with a higher VATI $\left(\geq 71 \mathrm{~cm}^{2} / \mathrm{m}^{2}\right)$ or higher FIRI $(\geq 5.5 \mu \mathrm{U} / \mathrm{mL})$ and $\operatorname{AFP}(\geq 11 \mathrm{ng} / \mathrm{mL})$ if VATI was $<71 \mathrm{~cm}^{2} / \mathrm{m}^{2}$ are prone to recurrence after curative treatment.

Keywords: fasting immunoreactive insulin; non-viral hepatocellular carcinoma; recurrence risk factor; visceral adipose tissue

\section{Introduction}

Hepatocellular carcinoma (HCC) is one of the most common global malignancies [1]. HCC generally develops in patients with chronic liver damage due to various causative agents, such as persistent infection of hepatitis B virus (HBV) and hepatitis C virus (HCV), alcohol consumption, and obesity and diabetes-related metabolic disorders [2]. Among them, HBV and HCV are the most common etiological factors worldwide for developing HCC. However, the cases caused by hepatitis virus infection are declining due to advances in anti-viral therapy [3-5].

On the other hand, with the increasing prevalence of obesity and diabetes in most countries, the increase in HCC associated with these factors recently has become a serious 
healthcare problem $[3,6]$. Approximately $20 \%$ of nonalcoholic fatty liver disease (NAFLD), hepatic manifestations of obesity, and metabolic syndrome, present as nonalcoholic steatohepatitis (NASH), with a risk of progression to cirrhosis and HCC [7]. HCC mortality is increasing in the United States partly because the number of patients with obesity and diabetes-related metabolic disorders is also increasing [3]. In Japan, non-B non-C HCC, which is diagnosed as both HBs antigen- and HCV antibody-negative, is also rapidly increasing, whereas HCV-related HCC is decreasing [6].

Cirrhosis usually precedes the diagnosis of HCC in most patients; however, it is not always a prerequisite for HCC development, and this might apply particularly to nonB non-C HCC [7]. One of the mechanisms through which non-cirrhotic HCC develops in obese and diabetic patients might be the involvement of obesity-related oncogenic drivers, such as adipose-derived inflammation, lipotoxicity, and insulin resistance [7]. In the overnutrition era, detection of non-cirrhotic HCC at an early stage, among immense numbers of obese patients who have neither $\mathrm{HBV}$ nor $\mathrm{HCV}$ is a major challenge. However, useful clinical risk factors affecting the development of non-B non-C HCC are still not fully understood.

Recurrent HCC is more likely to occur than initial HCC [8]. Therefore, it is useful to analyze the recurrence risk factors of HCC after curative treatment to identify the high-risk groups for this malignancy. Several factors, including male sex, presence of cirrhosis, high alpha-fetoprotein (AFP) levels, large tumor foci, multiplicity of tumors, and pathologically high-grade atypia of tumor cells, were reported to increase the recurrence risk for HCC after curative treatment [9-12]. In addition to these established recurrence risk factors, several obesity-related factors for pathogenesis, including a higher level of homeostasis model assessment-insulin resistance (HOMA-IR), increases in the serum levels of leptin and oxidative stress, and excess accumulation of visceral adipose tissue (VAT), were also reportedly involved in the early recurrence of HCC after curative treatment [13-16].

In this study, we investigated the factors that would affect recurrence-free survival in patients with non-B non-C HCC who have received curative treatment. To prevent oversight in any recurrence risk factors, we comprehensively selected possible risk factors associated with liver functional reserve, the progression of primary HCC, and obesity and diabetes, and performed a decision-tree analysis, which is a useful method for identifying the risk classification of HCC recurrence $[17,18]$.

\section{Materials and Methods}

\subsection{Patients, Treatment, and Determination of Recurrence}

HCC diagnosis was based on typical findings obtained by imaging modalities, including enhanced ultrasonography, dynamic computed tomography (CT), and dynamic magnetic resonance imaging (MRI). The selection criteria for the initial treatments were determined according to the guidelines for HCC by the Liver Cancer Study Group of Japan [19].

A total of 134 non-B non-C HCC patients were treated in our hospital between May 2006 and December 2019. Inclusion criteria were as follows-surgical resection or radiofrequency ablation (RFA) done as treatment for initial HCC and treatment effect diagnosed as curative by means of dynamic CT, MRI, or enhanced ultrasound examination. We excluded patients who could not follow-up at our hospital or suffered from other advanced cancers besides HCC. Finally, 72 patients were enrolled in this study. Patients were followed-up on an outpatient basis to assess imaging modalities, such as dynamic CT and MRI, which were performed every 3 months. Local recurrence was excluded in the present study, and only distant lesions were defined as recurrence. The recurrence-free survival time was defined as the interval from the date of the initial treatment to the date of recurrence, or until December 2019 for recurrence-free survivors. All study participants provided verbal informed consent, which was considered sufficient, as this study followed an observational research design that did not require new human biological specimens. The study 
design, including this consent procedure, was approved by the ethics committee of the Gifu University School of Medicine (ethical protocol code: 29-26).

\subsection{Decision-Tree Analysis of Risk Factors Affecting the Recurrence of Non-B Non-C HCC}

Decision-tree analysis [20] was performed to comprehensively measure as many possible risk factors for non-B non-C HCC recurrence as possible. We set the recurrencefree survival data, which consists of the observation time and the presence or absence of recurrence at the end of the observation, as an objective variable. On the other hand, the following factors were set as explanatory variables-(I) patients' information (age, sex, and drinking habit ( $\geq 60 \mathrm{~g} /$ day for men and $\geq 40 \mathrm{~g} /$ day for women in ethanol amount)); (II) body composition - body mass index (BMI), skeletal muscle index (SMI), subcutaneous adipose tissue (SAT) index (SATI), and VAT index (VATI); (III) liver functional reserveChild-Pugh score, albumin-bilirubin (ALBI) score, platelet count, Mac2 binding protein glucosylation isomer (M2BPGi), and the presence of cirrhosis; (IV) tumor factor-AFP, proteins induced by vitamin K absence or antagonist-II (PIVKA-II), clinical cancer stage, the degree of differentiation, the presence of vascular invasion, and initial treatment (resection or RFA); (V) metabolic syndrome-the presence of diabetes mellitus (DM), hyperlipidemia, and hypertension; and (VI) insulin resistance-fasting plasma glucose (FPG), fasting immunoreactive insulin (FIRI), HOMA-IR, and HbA1c. The outline of this study is shown in Figure 1.

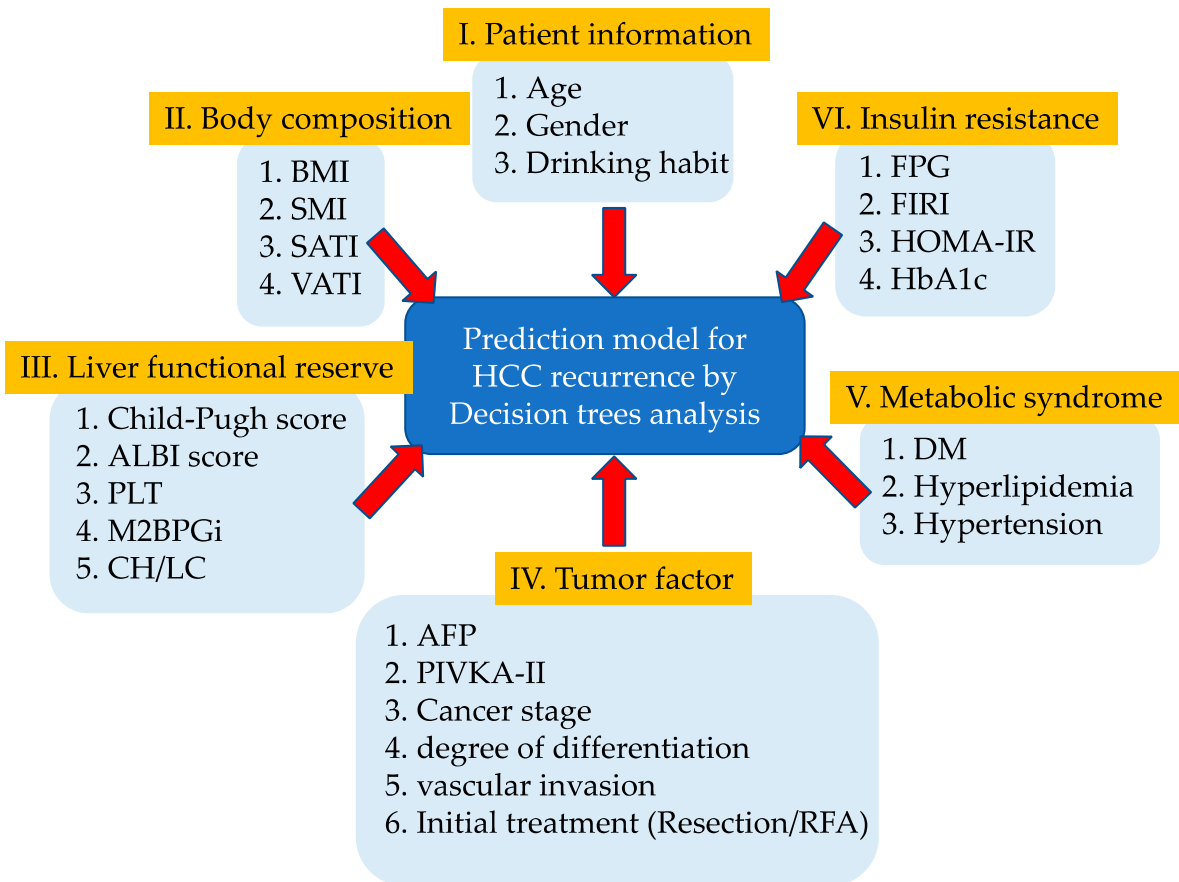

Figure 1. The outline of this study is based on the decision-tree analysis.

The cross-sectional areas of the muscle $\left(\mathrm{cm}^{2}\right)$ at the L3 level of the CT image were normalized by the square of the height $\left(\mathrm{m}^{2}\right)$ to obtain SMI $\left(\mathrm{cm}^{2} / \mathrm{m}^{2}\right)$. Similarly, the crosssectional areas of SAT and VAT $\left(\mathrm{cm}^{2}\right)$ at the umbilical point were normalized by the square of the height $\left(\mathrm{m}^{2}\right)$ to obtain the SATI and VATI $\left(\mathrm{cm}^{2} / \mathrm{m}^{2}\right)$, respectively [21]. We used the SYNAPSE VINCENT software (Fujifilm Medical, Tokyo, Japan) to measure the cross-sectional areas of these tissues.

\subsection{Statistical Analyses}

We used 'rpart' package (version 4.1-15) in R for conducting the decision-tree analysis. The settings for decision-tree analysis were as follows-method was ' $\exp ^{\prime}$; minimum number of observations was 25 ; complexity parameter was 0.02 ; other settings left the 
default value. Recurrence-free survival time was estimated using the Kaplan-Meier method. Differences between curves were evaluated using the log-rank test. The Cox proportionalhazards model was also used to confirm that the recurrence risk factors extracted using the decision-tree analysis would independently affect recurrence-free survival. The Tukey method was used as a post-hoc test to counteract the problem of multiple comparisons between the groups, divided by decision-tree analysis. Statistical significance was defined as $p<0.05$. All statistical analyses were performed using $\mathrm{R}$ version 4.0.0 ( $\mathrm{R}$ Foundation for Statistical Computing, Vienna, Austria; http:/ /www.R-project.org/, accessed on 26 March 2021).

\section{Results}

\subsection{Baseline Characteristics and Laboratory Data of Enrolled Patients}

The baseline characteristics and laboratory data of the 72 patients (49 males and 23 females; average age, 72.6 years) prior to the curative treatment for initial non- $\mathrm{B}$ non- $\mathrm{C}$ HCC are shown in Table 1. The median BMI and VATI were $24.7 \mathrm{~kg} / \mathrm{m}^{2}$ and $55.1 \mathrm{~cm}^{2} / \mathrm{m}^{2}$, respectively. Etiology was attributed to NASH $(66.7 \%)$, alcohol $(25.0 \%)$, and other factors $(8.3 \%)$. Of the enrolled patients, $75 \%$ were diagnosed with cirrhosis and $61.1 \%$ had diabetes.

Table 1. Baseline demographic and clinical characteristics of the enrolled patients on primary non-B non-C HCC.

\begin{tabular}{|c|c|}
\hline Variables & $(n=72)$ \\
\hline Sex (male/female) & $49 / 23$ \\
\hline Age (years) & $72.6 \pm 9.1$ \\
\hline Etiology (NASH/alcohol/others) & $48 / 18 / 6$ \\
\hline BMI $\left(\mathrm{kg} / \mathrm{m}^{2}\right)$ & $24.7 \pm 3.5$ \\
\hline $\operatorname{SMI}\left(\mathrm{cm}^{2} / \mathrm{m}^{2}\right)$ & $45.5 \pm 6.9$ \\
\hline SATI $\left(\mathrm{cm}^{2} / \mathrm{m}^{2}\right)$ & $46.8 \pm 28.0$ \\
\hline $\operatorname{VATI}\left(\mathrm{cm}^{2} / \mathrm{m}^{2}\right)$ & $55.1 \pm 26.5$ \\
\hline Drinking habit (yes/no) & $18 / 54$ \\
\hline DM (yes/no) & $44 / 28$ \\
\hline Hypertension (yes/no) & $39 / 33$ \\
\hline Hyperlipidemia (yes/no) & $17 / 55$ \\
\hline FPG & $119.3 \pm 36.4$ \\
\hline FIRI & $15.0 \pm 25.0$ \\
\hline HOMA-IR & $5.1 \pm 11.2$ \\
\hline $\mathrm{HbA1c}(\%)$ & $6.4 \pm 1.3$ \\
\hline Child-Pugh score $(5 / 6 / 7 / 8 / 9 / 10)$ & $49 / 16 / 4 / 1 / 1 / 1$ \\
\hline ALBI score & $-2.57 \pm 0.44$ \\
\hline Underlying liver disease (CH/LC) & $18 / 54$ \\
\hline M2BPGi & $1.9 \pm 1.8$ \\
\hline Stage (I/II/III/IV) & $20 / 13 / 28 / 0$ \\
\hline $\mathrm{AFP}(\mathrm{ng} / \mathrm{mL})$ & $878 \pm 3175$ \\
\hline PIVKA-II & $18,269 \pm 80,487$ \\
\hline $\begin{array}{c}\text { Degree of differentiation } \\
\text { (well/moderate/poor/unknown) }\end{array}$ & $6 / 33 / 7 / 26$ \\
\hline Capsule formation (yes/no/unknown) & $32 / 11 / 29$ \\
\hline Vascular invasion (yes/no) & $9 / 63$ \\
\hline Initial treatment (resection/RFA) & $47 / 25$ \\
\hline
\end{tabular}

Values are presented as mean \pm standard deviation. NASH, nonalcoholic steatohepatitis; BMI, body mass index SMI, skeletal muscle index; SATI, subcutaneous adipose tissue index; VATI, visceral adipose tissue index; DM, diabetes mellitus; FPG, fasting plasma glucose; FIRI, fasting immunoreactive insulin; HOMA-IR, homeostasis model assessment-insulin resistance; HbA1c, hemoglobin A1c; ALBI score, albumin and bilirubin score; $\mathrm{CH}_{r}$ chronic hepatitis; LC, liver cirrhosis; M2BPGi, Mac2 binding protein glucosylation isomer; AFP, alpha-fetoprotein; PIVKA-II, proteins induced by vitamin K absence or antagonist-II; and RFA, radiofrequency ablation.

\subsection{Possible Risk Factors Affecting Recurrence-Free Survival of Non-B Non-C HCC Patients}

The results of the decision-tree analysis are shown in Figure 2. Among the factors expected to be involved in the development of non-B non-C HCC (Figure 1), VATI $(<71$ 
and $\left.\geq 71 \mathrm{~cm}^{2} / \mathrm{m}^{2}\right)$, FIRI $(<5.5$ and $\geq 5.5 \mu \mathrm{U} / \mathrm{mL})$, and AFP $(<11$ and $\geq 11 \mathrm{ng} / \mathrm{mL})$ were identified as significant predictors for recurrence. The enrolled patients were also divided into four groups based on these three factors, which were associated with recurrence-free survival rates. The patients with VATI $\geq 71 \mathrm{~cm}^{2} / \mathrm{m}^{2}$ had the worst recurrence-free survival (Group 4, $n=16$ ). Among the remaining 56 patients, patients with $<5.5 \mu \mathrm{U} / \mathrm{mL}$ of FIRI had the best recurrence-free survival (Group 1, $n=17$ ). Among the remaining 39 patients who showed lower VATI $\left(<71 \mathrm{~cm}^{2} / \mathrm{m}^{2}\right)$ but higher FIRI $(\geq 5.5 \mu \mathrm{U} / \mathrm{mL})$, patients with $<11 \mathrm{ng} / \mathrm{mL}$ of AFP (Group 2, $n=20$ ) had better recurrence-free survival than those with $\geq 11 \mathrm{ng} / \mathrm{mL}$ (Group 3, $n=19$ ). The recurrence-free survival rates of the enrolled patients are described in the next section.

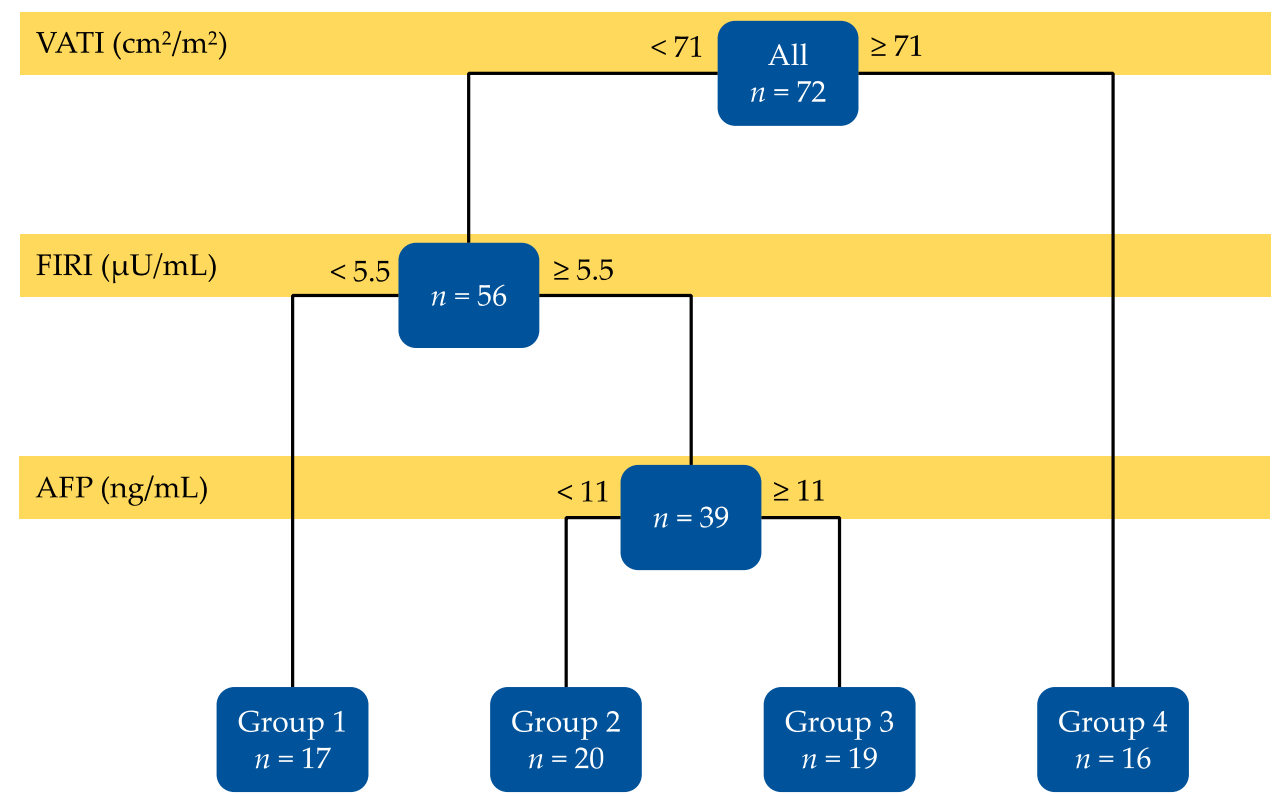

Figure 2. The result of the decision-tree analysis on factors predicting non-B non-C HCC recurrence.

The Cox proportional hazards model also showed that the three factors extracted using the decision-tree analysis including VATI ( $\geq 71$ vs. $<71 \mathrm{~cm}^{2} / \mathrm{m}^{2}$; hazard ratio (HR): 2.556, 95\% confidence interval (CI): 1.191-5.486, $p=0.016)$, FIRI ( $\geq 5.5$ vs. $<5.5 \mu \mathrm{U} / \mathrm{mL}$; HR: $3.149,95 \%$ CI: $1.156-8.575, p=0.025$ ), and AFP ( $\geq 11$ vs. $<11 \mathrm{ng} / \mathrm{mL}$; HR: 3.362, 95\% CI: $1.550-7.288, p=0.002)$, were all independent risk factors for HCC recurrence (Table 2). We also evaluated the same analyses stratified by gender. For males, the decision-tree analysis demonstrated that VATI $\left(<66\right.$ and $\left.\geq 66 \mathrm{~cm}^{2} / \mathrm{m}^{2}\right)$ and FIRI $(<5.5$ and $\geq 5.5 \mu \mathrm{U} / \mathrm{mL})$ were identified as significant predictors for recurrence (Supplemental Figure S1). The Cox proportional hazards model showed that VATI and AFP were independent risk factors (Supplemental Table S1). For females, neither the decision-tree analysis nor the Cox proportional hazards model extracted any significant predictor for $\mathrm{HCC}$ recurrence as the sample size was too small (Supplementary Table S2). 
Table 2. Univariate and multivariate analyses of possible risk factors affecting recurrence-free survival of non-B non-C HCC by Cox proportional hazards model.

\begin{tabular}{|c|c|c|c|c|}
\hline \multirow{2}{*}{ Variables } & \multicolumn{2}{|c|}{ Univariate Analysis } & \multicolumn{2}{|c|}{ Multivariate Analysis } \\
\hline & HR $(95 \% C I)$ & $p$ Value & HR $(95 \% C I)$ & $p$ Value \\
\hline Sex (male vs. female) & $0.398(0.699-2.795)$ & 0.343 & & \\
\hline Age (years) & $0.999(0.968-1.031)$ & 0.940 & & \\
\hline Drinking habit (yes vs. no) & $1.440(0.711-2.919)$ & 0.311 & & \\
\hline DM (yes vs. no) & $1.923(0.964-3.835)$ & 0.063 & & \\
\hline Hyperlipidemia (yes vs. no) & $1.100(0.503-2.407)$ & 0.811 & & \\
\hline Hypertension (yes vs. no) & $1.248(0.658-2.370)$ & 0.498 & & \\
\hline $\operatorname{VATI}\left(\geq 71\right.$ vs. $\left.<71\left(\mathrm{~cm}^{2} / \mathrm{m}^{2}\right)\right)$ & $2.718(1.381-5.349)$ & 0.004 & $\begin{array}{c}2.556 \\
(1.191-5.486)\end{array}$ & 0.016 \\
\hline Child-Pugh score & $1.104(0.787-1.548)$ & 0.568 & & \\
\hline $\operatorname{PLT}\left(\times 10^{4} / \mathrm{mL}\right)$ & $1.001(0.961-1.043)$ & 0.947 & & \\
\hline FIRI $(\geq 5.5$ vs. $<5.5(\mu \mathrm{U} / \mathrm{mL}))$ & $2.805(1.065-7.388)$ & 0.037 & $\begin{array}{c}3.149 \\
(1.156-8.575)\end{array}$ & 0.025 \\
\hline LC (yes vs. no) & $1.422(0.623-3.242)$ & 0.403 & & \\
\hline $\operatorname{AFP}(\geq 11$ vs. $<10(\mathrm{ng} / \mathrm{mL}))$ & $2.171(1.131-4.166)$ & 0.020 & $\begin{array}{c}3.362 \\
(1.550-7.288)\end{array}$ & 0.002 \\
\hline $\begin{array}{l}\text { Degree of differentiation } \\
\text { (moderate vs. well) }\end{array}$ & $2.794(0.646-12.08)$ & 0.169 & & \\
\hline (poor vs. well) & $3.471(0.626-19.26)$ & 0.155 & & \\
\hline Vascular invasion (yes vs. no) & $2.237(0.972-5.152)$ & 0.058 & & \\
\hline Initial treatment (RFA vs. Resection) & $0.923(0.467-1.824)$ & 0.818 & & \\
\hline
\end{tabular}

HR, hazard ratio; DM, diabetes mellitus; VATI, visceral adipose tissue index; PLT, platelet count; FIRI, fasting immunoreactive insulin; LC, liver cirrhosis; AFP alpha-fetoprotein; and RFA, radiofrequency ablation.

\subsection{Recurrence-Free Survival Rates of the Enrolled Patients}

The Kaplan-Meier method showed that the 1-, 3-, and 5-year recurrence-free survival rates of all enrolled patients were $63.8 \%, 43.0 \%$, and $33.3 \%$, respectively (Figure $3 a$ ). These rates for each respective group divided according to the decision-tree analysis were $92.3 \%$, $92.3 \%$, and $76.9 \%$ (Group 1); $78.3 \%, 66.1 \%$, and $55.1 \%$ (Group 2); $45.3 \%, 22.7 \%$, and $11.3 \%$ (Group 3); and 40.2\%, 0\%, and 0\% (Group 4), respectively. Patients in Group 1 had significantly better recurrence-free survival than those in Group $3(p<0.01)$ and Group $4(p<0.01)$, as per the log-rank test results. The recurrence-free survival of Group 1 also tended to be better than that of Group $2(p=0.08$, Figure $3 b)$. When comparing the differences of baseline demographic and clinical characteristics among the four groups, there were significant differences in BMI, SMI, and VATI (Table 3); however, no significant differences were found in the other factors including AFP and FIRI. The level of AFP $(<11$ and $\geq 11 \mathrm{ng} / \mathrm{mL}$ ) was not involved in the recurrence free survival of the patients in Group 1 (Supplemental Figure S2a). Additionally, the levels of AFP $(<11$ and $\geq 11 \mathrm{ng} / \mathrm{mL})$ and FIRI $(<5.5$ and $\geq 5.5 \mu \mathrm{U} / \mathrm{mL})$ did not affect the recurrence free survival of the patients in Group 4 (Supplementary Figure S2b,c). 
Table 3. Baseline demographic and clinical characteristics of the enrolled patients with primary non-B non-C HCC divided into four groups according to the decision-tree analysis

\begin{tabular}{|c|c|c|c|c|c|}
\hline Variables & Group $1(n=17)$ & Group $2(n=20)$ & Group $3(n=19)$ & Group $4(n=16)$ & $P$ Value \\
\hline Sex (male/female) & $12 / 5$ & $13 / 7$ & $12 / 7$ & $12 / 4$ & 0.873 \\
\hline Age (years) & $72.2 \pm 12.3$ & $72.3 \pm 10.5$ & $71.4 \pm 6.6$ & $74.8 \pm 5.7$ & 0.729 \\
\hline Etiology (NASH/alcohol/others) & $12 / 5 / 0$ & $14 / 4 / 2$ & $9 / 8 / 2$ & $13 / 1 / 2$ & 0.105 \\
\hline BMI $\left(\mathrm{kg} / \mathrm{m}^{2}\right)$ & $21.4 \pm 2.7$ & $25.0 \pm 2.1$ & $25.6 \pm 3.6$ & $26.9 \pm 3.3$ & $<0.001$ \\
\hline $\operatorname{SMI}\left(\mathrm{cm}^{2} / \mathrm{m}^{2}\right)$ & $40.0 \pm 3.6$ & $44.8 \pm 7.6$ & $48.1 \pm 6.6$ & $48.9 \pm 5.6$ & $<0.001$ \\
\hline SATI $\left(\mathrm{cm}^{2} / \mathrm{m}^{2}\right)$ & $34.5 \pm 18.4$ & $48.7 \pm 21.4$ & $50.5 \pm 29.1$ & $53.1 \pm 38.6$ & 0.209 \\
\hline $\operatorname{VATI}\left(\mathrm{cm}^{2} / \mathrm{m}^{2}\right)$ & $34.2 \pm 14.2$ & $50.9 \pm 14.0$ & $48.2 \pm 17.4$ & $90.7 \pm 23.8$ & $<0.001$ \\
\hline Drinking habit (yes/no) & $5 / 12$ & $4 / 16$ & $8 / 11$ & $1 / 15$ & 0.093 \\
\hline DM (yes/no) & $8 / 9$ & $11 / 9$ & $13 / 6$ & $12 / 4$ & 0.327 \\
\hline Hypertension (yes/no) & $8 / 9$ & $8 / 12$ & $13 / 6$ & $10 / 6$ & 0.265 \\
\hline Hyperlipidemia (yes/no) & $4 / 13$ & $2 / 18$ & $6 / 13$ & $5 / 11$ & 0.356 \\
\hline FPG & $113.6 \pm 43.8$ & $117.1 \pm 24.1$ & $113.1 \pm 28.6$ & $135.3 \pm 46.1$ & 0.250 \\
\hline FIRI & $3.9 \pm 0.9$ & $22.8 \pm 33.0$ & $19.8 \pm 30.8$ & $11.7 \pm 13.0$ & 0.124 \\
\hline HOMA-IR & $1.1 \pm 0.6$ & $6.7 \pm 10.3$ & $7.3 \pm 17.1$ & $4.7 \pm 8.5$ & 0.389 \\
\hline $\mathrm{HbA1c}(\%)$ & $6.3 \pm 1.5$ & $6.4 \pm 1.1$ & $6.2 \pm 1.0$ & $7.0 \pm 1.6$ & 0.277 \\
\hline Child-Pugh score $(5 / 6 / 7 / 8 / 9 / 10)$ & $12 / 3 / 1 / 0 / 0 / 1$ & $12 / 6 / 2 / 0 / 0 / 0$ & $12 / 4 / 1 / 1 / 1 / 0$ & $13 / 3 / 0 / 0 / 0 / 0$ & 0.686 \\
\hline ALBI score & $-2.52 \pm 0.44$ & $-2.56 \pm 0.45$ & $-2.58 \pm 0.47$ & $-2.64 \pm 0.45$ & 0.890 \\
\hline $\begin{array}{l}\text { Underlying liver disease } \\
\qquad(\mathrm{CH} / \mathrm{LC})\end{array}$ & $7 / 10$ & $4 / 16$ & $4 / 15$ & $3 / 13$ & 0.372 \\
\hline M2BPGi & $1.4 \pm 0.6$ & $1.6 \pm 0.9$ & $2.7 \pm 3.1$ & $1.8 \pm 1.3$ & 0.408 \\
\hline Stage (I/II/III/IV) & $2 / 10 / 3 / 2$ & $8 / 9 / 3 / 0$ & $4 / 6 / 8 / 1$ & $3 / 6 / 7 / 0$ & 0.141 \\
\hline $\mathrm{AFP}(\mathrm{ng} / \mathrm{mL})$ & $1686 \pm 3782$ & $5.6 \pm 2.3$ & $541 \pm 997$ & $1510 \pm 5379$ & 0.331 \\
\hline PIVKA-II & $12375 \pm 48613$ & $3242 \pm 8843$ & $18528 \pm 72059$ & $40205 \pm 140137$ & 0.609 \\
\hline $\begin{array}{c}\text { Degree of differentiation } \\
\text { (well/moderate/poor/unknown) }\end{array}$ & $2 / 7 / 2 / 6$ & $3 / 6 / 1 / 10$ & $1 / 10 / 1 / 7$ & $0 / 10 / 3 / 3$ & 0.419 \\
\hline $\begin{array}{l}\text { Capsule formation } \\
\text { (yes/no/unknown) }\end{array}$ & $9 / 2 / 6$ & $7 / 3 / 10$ & $7 / 3 / 9$ & $9 / 3 / 4$ & 0.914 \\
\hline Vascular invasion (yes/no) & $3 / 14$ & $0 / 20$ & $3 / 16$ & $3 / 13$ & 0.258 \\
\hline Initial treatment (resection/RFA) & $11 / 6$ & $11 / 9$ & $13 / 6$ & $12 / 4$ & 0.662 \\
\hline
\end{tabular}

Values are presented as mean \pm standard deviation. NASH, nonalcoholic steatohepatitis; BMI, body mass index; SMI, skeletal muscle index; SATI, subcutaneous adipose tissue index; VATI, visceral adipose tissue index; DM, diabetes mellitus; FPG, fasting plasma glucose; FIRI, fasting immunoreactive insulin; HOMA-IR, homeostasis model assessment-insulin resistance; HbA1c, hemoglobin A1c; ALBI score, albumin and bilirubin score; $\mathrm{CH}$, chronic hepatitis; LC, liver cirrhosis; M2BPGi, Mac2 binding protein glucosylation isomer; AFP, alpha-fetoprotein; PIVKA-II, proteins induced by vitamin K absence or antagonist-II; and RFA, radiofrequency ablation.

(a)

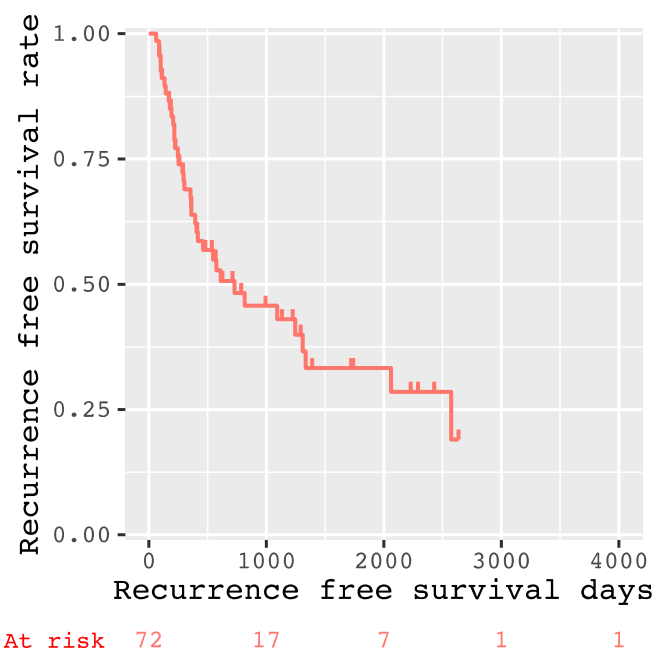

(b)

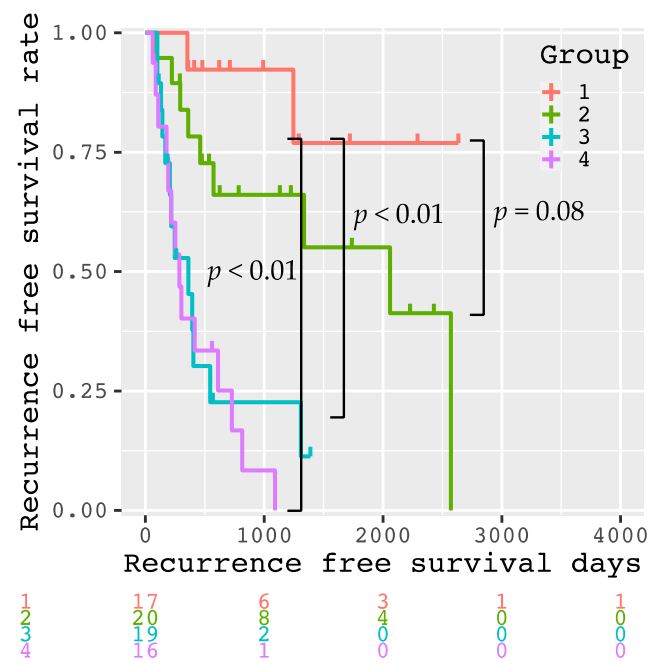

Figure 3. Kaplan-Meier curves for recurrence-free survival after curative treatment in all participants (a), and divided into four groups according to the decision-tree analysis (b). Group 1 meets the following conditions: VATI $<71 \mathrm{~cm}^{2} / \mathrm{m}^{2}$ and FIRI $<5.5 \mu \mathrm{U} / \mathrm{mL}$; Group 2: VATI $<71 \mathrm{~cm}^{2} / \mathrm{m}^{2}$, FIRI $\geq 5.5 \mu \mathrm{U} / \mathrm{mL}$, and AFP $<11 \mathrm{ng} / \mathrm{mL}$; Group $3:$ VATI $<71 \mathrm{~cm}^{2} / \mathrm{m}^{2}$, FIRI $\geq 5.5 \mu \mathrm{U} / \mathrm{mL}$, and AFP $\geq 11 \mathrm{ng} / \mathrm{mL}$; and Group 4 : VATI $\geq 71 \mathrm{~cm}^{2} / \mathrm{m}^{2}$. 
The 1-, 3-, and 5-year overall survival rates of all enrolled patients were $92.1 \%, 72.3 \%$, and $47.0 \%$, respectively (Supplementary Figure S3a). Although there were not significant differences in overall survival among the four groups $(p=0.087)$, patients in Group 1 and 2 tended to have longer survival than those in Group 3 and 4. (Supplementary Figure S3b).

\section{Discussion}

Obesity is a serious healthcare problem worldwide [22,23]. A large number of studies revealed a link between obesity and the development of HCC [22,24]. The number of patients with NAFLD/NASH are reportedly increasing, and HCC can often emerge in the non-cirrhotic liver among obese NAFLD/NASH patients [7,25]. In this study, none of the factors associated with liver functional reserve were risk factors for non-B non-C HCC recurrence. These include the Child-Pugh score, ALBI score, platelet count, M2BPGi, and the presence of cirrhosis, which significantly increase the risk of developing virusassociated HCC [10]. These facts suggest that the conventional surveillance strategies for HCC mainly targeted at cirrhotic patients with HBV or HCV might be insufficient in the overnutrition era. Therefore, finding suitable obesity-related HCC risk factors based on the consideration of the mechanism that links obesity to liver carcinogenesis is urgently needed for screening the development of virus-negative HCC.

The results of the decision-tree analysis conducted in this cohort clearly showed that the excess accumulation of VAT $\left(\geq 71 \mathrm{~cm}^{2} / \mathrm{m}^{2}\right)$ was the strongest risk factor for non-B non$\mathrm{C}$ HCC recurrence. Accumulation of VAT, which involves the recruitment of macrophages, is considered to play a critical role in liver carcinogenesis $[7,26]$. VAT leads to an altered pattern of adipokine secretion, which is involved in systemic inflammation, tumor growth, and angiogenesis $[7,27]$. Insulin resistance or hyperinsulinemia, which are often seen in patients with a high volume of VAT, also promotes the development of HCC through the activation of tumor growth and angiogenesis [7]. Consistent with these mechanisms, we observed in the present study that the patients in Group 1 who have lower VAT $\left(<71 \mathrm{~cm}^{2} / \mathrm{m}^{2}\right)$ and FIRI $(<5.5 \mu \mathrm{U} / \mathrm{mL})$ exhibited the best prognosis without experiencing HCC recurrence.

A high BMI is reportedly associated with an increased risk of HCC development [28]. However, our findings on how the accumulation of VAT predicts the recurrence of non-B non-C HCC suggest that in addition to BMI, more attention should be paid to body fat distribution, in order to screen patients who have a high risk of developing HCC. The physiological functions of VAT and SAT are quite different. Fat cells in SAT act as a buffer or sink for circulating free fatty acids and triglycerides. SAT might also be used as an energy source when receiving chemotherapy for HCC, and its rapid depletion predicts the poor survival of these patients [21,29]. Therefore, a body fat distribution assessment might be useful in predicting high-risk and poor prognosis groups for HCC.

Hyperinsulinemia was the second strongest predictor of non-B non-C HCC recurrence, whereas the FPG, HOMA-IR, and HbA1c values were not. This suggests that insulin itself is more deeply involved in liver carcinogenesis than insulin resistance and serum glucose levels. Our findings were consistent with the results of previous reports showing that insulin and insulin-stimulating drugs, such as sulfonylurea, significantly increase the risk of HCC [30,31]. According to the meta-analysis, metformin use was associated with a $50 \%$ reduction in the risk of developing HCC, whereas sulfonylurea or insulin use was associated with a $62 \%$ and $161 \%$ increase in the risk of HCC, respectively [30]. Insulin can stimulate the growth of HCC cells and promote vascular invasion of the tumor [7]. Together with these previous studies, this study might imply that we should treat diabetic patients with potential risk of HCC development with anti-diabetic medications that do not lead to hyperinsulinemia. In the present study, higher levels of both FIRI and AFP were associated with an increased risk of non-B non-C HCC recurrence. as high AFP levels reportedly indicate more severe vascular invasion and the existence of minute lesions that cannot be detected by imaging modalities [10], microvascular invasion or the growth of microtumors might be accelerated by hyperinsulinemia, especially in these patients. 
This study has several limitations. First, it was a retrospective, single-center study, and the sample size was small as compared to those of the previous studies, showing the usefulness of decision-tree analysis for detecting a high-risk group for HCC recurrence [17,18]. For instance, according to the documentation that estimates sample sizes for the comparison of survival curves by the log-rank statistic [32], we need a sample size of about 200 if we want to compare a patient group with two years median recurrence free survival to one with three years. Second, this study did not focus on initial HCC, but on recurrent HCC after curative treatment. Thus, it might include a certain number of intrahepatic metastasis cases, which can impair the reliability of assessing the risk of hepatocarcinogenesis itself. We should analyze cases of cancer-free liver diseases other than HBV or HCV-related hepatitis, in order to purely estimate the risk of non-viral hepatocarcinogenesis. However, at the moment, such analysis seems difficult because risk factors of non-viral HCC are not clearly defined and we cannot screen the immense number of patients in the high-risk group of obese who neither have HBV nor HCV. Third, VATI presented as the strongest risk factor in this study is not a simple and safe index because a CT must be performed to obtain VATI. It is not realistic to perform a CT for all obese people. To overcome these limitations, a prospective study involving a larger number of non-B non-C patients without HCC enrolled from several centers should be conducted in the future.

\section{Conclusions}

The decision-tree analysis showed that non-B non-C HCC patients with a higher VATI $\left(\geq 71 \mathrm{~cm}^{2} / \mathrm{m}^{2}\right)$, and higher serum levels of insulin $(\geq 5.5 \mu \mathrm{U} / \mathrm{mL})$ and AFP $(\geq 11 \mathrm{ng} / \mathrm{mL})$ are prone to recurrence after curative treatment. Since the number of obese people is currently increasing rapidly worldwide, obesity or diabetes-related risk factors (VATI and FIRI), together with the established risk factors (AFP) for HCC recurrence might be useful in screening obese patients with a higher risk of HCC development and recurrence. Future studies enrolling a larger number of patients are important to verify the effects of these factors on the development of non-B non-C HCC.

Supplementary Materials: The following are available online at https:/ / www.mdpi.com/article/10 .3390 / cancers13071542/s1. Figure S1: The result of the decision-tree analysis on factors predicting non-B non-C HCC recurrence for men. Figure S2. Kaplan-Meier curves for recurrence-free survival after curative treatment in Group 1 divided into the cutoff value (11 ng/mL) of AFP (a), those in Group 4 divided into the cutoff value $(11 \mathrm{mg} / \mathrm{mL})$ of AFP (b), and those in Group 4 divided into the cutoff value $(5.5 \mu \mathrm{U} / \mathrm{mL}$ ) of FIRI (c); Figure S3. Kaplan-Meier curves for overall survival after curative treatment in all participants (a), and divided into four groups according to the decision-tree analysis (b). Group 1 meets the following conditions: VATI $<71 \mathrm{~cm}^{2} / \mathrm{m}^{2}$ and FIRI $<5.5 \mu \mathrm{U} / \mathrm{mL}$; Group 2: VATI $<71 \mathrm{~cm}^{2} / \mathrm{m}^{2}$, FIRI $\geq 5.5 \mu \mathrm{U} / \mathrm{mL}$, and AFP $<11 \mathrm{ng} / \mathrm{mL}$; Group 3: VATI $<71 \mathrm{~cm}^{2} / \mathrm{m}^{2}$, FIRI $\geq 5.5 \mu \mathrm{U} / \mathrm{mL}$, and AFP $\geq 11 \mathrm{ng} / \mathrm{mL}$; Group 4 : VATI $\geq 71 \mathrm{~cm}^{2} / \mathrm{m}^{2}$. Table S1: Univariate and multivariate analyses of possible risk factors for men affecting recurrence-free survival of non-B non-C HCC by Cox proportional hazards model. Table S2. Univariate and multivariate analyses of possible risk factors for women affecting recurrence-free survival of non-B non-C HCC by Cox proportional hazards model.

Author Contributions: K.I., K.T., T.M. (Takao Miwa), T.M. (Toshihide Maeda), T.H., A.S., M.S. (Makoto Shiraki), and M.S. (Masahito Shimizu) designed the study. K.I. analyzed the data and drafted the manuscript. K.T. supervised the treatment of the participants. K.T., T.M. (Takao Miwa), T.M. (Toshihide Maeda), A.S., and M.S. (Makoto Shiraki) contributed to the selection of the participants and collected the data. K.T., T.M. (Takao Miwa), T.M. (Toshihide Maeda), A.S., and M.S. (Makoto Shiraki) revised the manuscript, and M.S. (Masahito Shimizu) mainly reviewed and amended the manuscript. All authors have read and agreed to the published version of the manuscript.

Funding: This research received no external funding.

Institutional Review Board Statement: The study design, including this consent procedure, was approved by the ethics committee of the Gifu University School of Medicine (ethical protocol code: 29-26). 
Informed Consent Statement: All study participants provided verbal informed consent, which was considered sufficient as this study followed an observational research design that did not require new human biological specimens.

Data Availability Statement: The data presented in this study are available on request from the corresponding author.

Conflicts of Interest: The authors declare no conflict of interest.

\section{References}

1. El-Serag, H.B. Hepatocellular carcinoma. N. Engl. J. Med. 2011, 365, 1118-1127. [CrossRef]

2. El-Serag, H.B. Hepatocellular carcinoma: An epidemiologic view. J. Clin. Gastroenterol. 2002, 35, S72-S78. [CrossRef]

3. Bertuccio, P.; Turati, F.; Carioli, G.; Rodriguez, T.; La Vecchia, C.; Malvezzi, M.; Negri, E. Global trends and predictions in hepatocellular carcinoma mortality. J. Hepatol. 2017, 67, 302-309. [CrossRef]

4. Imai, K.; Takai, K.; Hanai, T.; Suetsugu, A.; Shiraki, M.; Shimizu, M. Sustained virological response by direct-acting antivirals reduces the recurrence risk of hepatitis C-related hepatocellular carcinoma after curative treatment. Mol. Clin. Oncol. 2019, 111-116. [CrossRef]

5. $\quad$ Liaw, Y.F.; Sung, J.J.Y.; Chow, W.C.; Farrell, G.; Lee, C.Z.; Yuen, H.; Tanwandee, T.; Tao, Q.M.; Shue, K.; Keene, O.N.; et al. Lamivudine for patients with chronic hepatitis B and advanced liver disease. N. Engl. J. Med. 2004. [CrossRef] [PubMed]

6. Tateishi, R.; Uchino, K.; Fujiwara, N.; Takehara, T.; Okanoue, T.; Seike, M.; Yoshiji, H.; Yatsuhashi, H.; Shimizu, M.; Torimura, T.; et al. A nationwide survey on non-B, non-C hepatocellular carcinoma in Japan: 2011-2015 update. J. Gastroenterol. 2019, 54, 367-376. [CrossRef] [PubMed]

7. Karagozian, R.; Derdak, Z.; Baffy, G. Obesity-associated mechanisms of hepatocarcinogenesis. Metabolism 2014, 63, 607-617. [CrossRef] [PubMed]

8. Poon, R.T. Prevention of recurrence after resection of hepatocellular carcinoma: A daunting challenge. Hepatology 2011, 54, 757-759. [CrossRef]

9. Nagashima, I.; Hamada, C.; Naruse, K.; Osada, T.; Nagao, T.; Kawano, N.; Muto, T. Surgical resection for small hepatocellular carcinoma. Surgery 1996, 119, 40-45. [CrossRef]

10. Koike, Y.; Shiratori, Y.; Sato, S.; Obi, S.; Teratani, T.; Imamura, M.; Hamamura, K.; Imai, Y.; Yoshida, H.; Shiina, S.; et al. Risk factors for recurring hepatocellular carcinoma differ according to infected hepatitis virus-an analysis of 236 consecutive patients with a single lesion. Hepatology 2000, 32, 1216-1223. [CrossRef] [PubMed]

11. Ikeda, K.; Saitoh, S.; Tsubota, A.; Arase, Y.; Chayama, K.; Kumada, H.; Watanabe, G.; Tsurumaru, M. Risk factors for tumor recurrence and prognosis after curative resection of hepatocellular carcinoma. Cancer 1993, 71, 19-25. [CrossRef]

12. Adachi, E.; Maeda, T.; Matsumata, T.; Shirabe, K.; Kinukawa, N.; Sugimachi, K.; Tsuneyoshi, M. Risk factors for intrahepatic recurrence in human small hepatocellular carcinoma. Gastroenterology 1995, 108, 768-775. [CrossRef]

13. Imai, K.; Takai, K.; Hanai, T.; Suetsugu, A.; Shiraki, M.; Shimizu, M. Homeostatic Model Assessment of Insulin Resistance for Predicting the Recurrence of Hepatocellular Carcinoma after Curative Treatment. Int. J. Mol. Sci. 2019, 20, 605. [CrossRef] [PubMed]

14. Watanabe, N.; Takai, K.; Imai, K.; Shimizu, M.; Naiki, T.; Nagaki, M.; Moriwaki, H. Increased levels of serum leptin are a risk factor for the recurrence of stage I/II hepatocellular carcinoma after curative treatment. J. Clin. Biochem. Nutr. 2011, 49, 153-158. [CrossRef] [PubMed]

15. Suzuki, Y.; Imai, K.; Takai, K.; Hanai, T.; Hayashi, H.; Naiki, T.; Nishigaki, Y.; Tomita, E.; Shimizu, M.; Moriwaki, H. Hepatocellular carcinoma patients with increased oxidative stress levels are prone to recurrence after curative treatment: A prospective case series study using the d-ROM test. J. Cancer Res. Clin. Oncol. 2013, 139, 845-852. [CrossRef]

16. Imai, K.; Takai, K.; Maeda, T.; Watanabe, S.; Hanai, T.; Suetsugu, A.; Shiraki, M.; Shimizu, M. Increased visceral fat volume raises the risk for recurrence of hepatocellular carcinoma after curative treatment. Oncotarget 2018, 9, 14058-14067. [CrossRef]

17. Tanaka, T.; Kurosaki, M.; Lilly, L.B.; Izumi, N.; Sherman, M. Identifying candidates with favorable prognosis following liver transplantation for hepatocellular carcinoma: Data mining analysis. J. Surg. Oncol. 2015, 112, 72-79. [CrossRef]

18. Feng, L.H.; Sun, H.C.; Zhu, X.D.; Liu, X.F.; Zhang, S.Z.; Li, X.L.; Li, Y.; Tang, Z.Y. Prognostic nomograms and risk classifications of outcomes in very early-stage hepatocellular carcinoma patients after hepatectomy. Eur. J. Surg. Oncol. 2020, 47, 681-689. [CrossRef]

19. Kudo, M.; Matsui, O.; Izumi, N.; Iijima, H.; Kadoya, M.; Imai, Y.; Okusaka, T.; Miyayama, S.; Tsuchiya, K.; Ueshima, K.; et al. JSH Consensus-Based Clinical Practice Guidelines for the Management of Hepatocellular Carcinoma: 2014 Update by the Liver Cancer Study Group of Japan. Liver Cancer 2014, 3, 458-468. [CrossRef]

20. Quinlan, J.R. Induction of decision trees. Mach. Learn. 1986, 1, 81-106. [CrossRef]

21. Imai, K.; Takai, K.; Miwa, T.; Taguchi, D.; Hanai, T.; Suetsugu, A.; Shiraki, M.; Shimizu, M. Rapid depletion of subcutaneous adipose tissue during sorafenib treatment predicts poor survival in patients with hepatocellular carcinoma. Cancers 2020, 12, 1795. [CrossRef] [PubMed]

22. Calle, E.E.; Rodriguez, C.; Walker-Thurmond, K.; Thun, M.J. Overweight, obesity, and mortality from cancer in a prospectively studied cohort of U.S. adults. N. Engl. J. Med. 2003, 348, 1625-1638. [CrossRef] 
23. Wang, Y.C.; McPherson, K.; Marsh, T.; Gortmaker, S.L.; Brown, M. Health and economic burden of the projected obesity trends in the USA and the UK. Lancet 2011, 378, 815-825. [CrossRef]

24. Samanic, C.; Chow, W.H.; Gridley, G.; Jarvholm, B.; Fraumeni, J.F. Relation of body mass index to cancer risk in 362,552 Swedish men. Cancer Causes Control 2006. [CrossRef] [PubMed]

25. Sanyal, A.; Poklepovic, A.; Moyneur, E.; Barghout, V. Population-based risk factors and resource utilization for HCC: US perspective. Curr. Med. Res. Opin. 2010. [CrossRef]

26. Shimizu, M.; Tanaka, T.; Moriwaki, H. Obesity and hepatocellular carcinoma: Targeting obesity-related inflammation for chemoprevention of liver carcinogenesis. Semin. Immunopathol. 2013, 35, 191-202. [CrossRef] [PubMed]

27. Shoelson, S.E.; Herrero, L.; Naaz, A. Obesity, inflammation, and insulin resistance. Gastroenterology 2007, 132, 2169-2180. [CrossRef]

28. Muto, Y.; Sato, S.; Watanabe, A.; Moriwaki, H.; Suzuki, K.; Kato, A.; Kato, M.; Nakamura, T.; Higuchi, K.; Nishiguchi, S.; et al. Overweight and obesity increase the risk for liver cancer in patients with liver cirrhosis and long-term oral supplementation with branched-chain amino acid granules inhibits liver carcinogenesis in heavier patients with liver cirrhosis. Hepatol. Res. 2006, 35, 204-214. [CrossRef] [PubMed]

29. Imai, K.; Takai, K.; Miwa, T.; Taguchi, D.; Hanai, T.; Suetsugu, A. Rapid Depletions of Subcutaneous Fat Mass and Skeletal Muscle Mass Predict Worse Survival in Patients with Hepatocellular Carcinoma Treated with Sorafenib. Cancers 2019, 11, 1206. [CrossRef]

30. Singh, S.; Singh, P.P.; Singh, A.G.; Murad, M.H.; Sanchez, W. Anti-diabetic medications and the risk of hepatocellular cancer: A systematic review and meta-analysis. Am. J. Gastroenterol. 2013, 108, 881-891, quiz 892. [CrossRef]

31. Zhou, Y.Y.; Zhu, G.Q.; Liu, T.; Zheng, J.N.; Cheng, Z.; Zou, T.T.; Braddock, M.; Fu, S.W.; Zheng, M.H. Systematic Review with Network Meta-Analysis: Antidiabetic Medication and Risk of Hepatocellular Carcinoma. Sci. Rep. 2016, 6, 1-10. [CrossRef] [PubMed]

32. Lakatos, E. Sample sizes based on the log-rank statistic in complex clinical trials. Biometrics 1988, 44, 229-241. [CrossRef] [PubMed] 